\title{
Induction of Androgenesis in Pearl Millet
}

\author{
Panchangam Sameera Sastry ${ }^{1, *}$, Nalini Mallikarjuna ${ }^{2}$ \\ ${ }^{1}$ Jawarharlal Nehru Institute of Advanced studies, Secunderabad, A.P, India \\ ${ }^{2}$ International Crops Research Institute for the Semi-Arid Tropics, Patancheru, India \\ *Corresponding Author: sameera.panchangam@gmail.com
}

Copyright (C) 2014 Horizon Research Publishing All rights reserved.

\begin{abstract}
Breeding efforts in Pearl millet (Pennisetum glaucum (L.) R.Br), one of the most widely cultivated drought- and high-temperature tolerant $\mathrm{C} 4$ cereals, are aimed at maximum exploitation of hybrid vigor for both grain and forage yields. Until now, very limited work has been carried out on in vitro production of haploids in pearl millet; while it is being employed as the pollinator which will be further eliminated, resulting in haploids of the recipient species, e.g. wheat, oat. Anther culture experiments were carried out with seven genotypes 841-P3, 843-22B, ICMB 93333, ICMB 89111, XL-51, 4201 and 86-M34 tested on 12 different culture media. Androgenic embryos were induced in the frequency of $13.7,9.51$ and $7.58 \%$ from 841-P3, ICMB 93333 and XL-51 cultivars. Inclusion of $4 \%$ maltose as additional carbon source resulted in higher number of multicellular microspores among the responsive genotypes. These experiments form a promising basis to further develop double haploid protocol for pearl mille breeding in the arid and semi-arid regions.
\end{abstract}

Keywords Anther Culture, Pearl Millet, Double Haploids, Pro-Embryo

\section{Introduction}

Pearl millet (Pennisetum glaucum (L.) R. Br) is one of the most widely cultivated drought- and high-temperature tolerant $\mathrm{C} 4$ cereals. If pulse is the poor man's meat, millet is the poor man's bread. It is equal or even superior to rice and maize in protein and oil content (http://www.cgiar.org/our-research/crop-factsheets/millets/). Breeding efforts in pearl millet are aimed at maximum exploitation of hybrid vigor for both grain and forage yields. Hybrid parents are bred mostly by recurrent selection which is based on the natural out-breeding behavior of the crop; or by pedigree breeding from populations that have mostly been derived from single crosses. This approach continues to be widely used and quite successful, although the obvious effect is narrowing of the genetic base of hybrid cultivars. Cultivars developed from OPVs (open pollinated varieties) and hybrids are highly heterogenous and heterozygous, open to significant genetic changes. Such cultivars developed from single progenies are marred by inbreeding depression and loss of vigor (Rai et al. 1999). Though NILs and RILs hold great importance in breeding and mapping for traits, their limitations are the long time and/or high cost required for development, and these populations only detect the additive component but do not provide information on dominance relationships for any QTL (Semagn et al. 2010). On the other hand, DH are quicker to generate than NILs and RILs, and they can also be used to generate NILs (Mithila and Hall 2003).

Pearl millet is being exploited in breeding programs to develop DH but merely as the pollinator which will be further eliminated, resulting in haploids of the recipient species, eg. wheat, oat etc. (Marcinska et al. 2012). Until now, very limited work is carried out on in vitro production of haploids in pearl millet (Dang Ha and Pernes, 1982; Nitsch, 1982; Choi et al. 1989). Ha and Pernes (1982) were the first to report successful in vitro androgenic haploids in pearl millet lines Tifl23D2B and a F1 hybrid. In the same year, Nitsch (1982) reported haploid regeneration from in vitro cultures of anthers. Vasil and Haydu (1981) carried out studies on somatic embryogenesis of a related species Pennisetum purpureum and obtained diploids from in vitro culture of anthers. However, the entire regenerated plants were from the cells derived from the anther wall. Mallikarjuna (1987) examined the suitability of different culture media for pearl millet anther culture and obtained multicellular microspores on MS media, but regeneration of whole plants was not achieved. Further efforts are demonstrated by one report (Choi et al. 1989), which focused on two genotypes for refining the technique of androgenesis and regeneration. Considering the fact that most successful protocols for DH through anther and/or microspore culture belong to cereal species i.e. rice, barley, wheat and maize; only sporadic work has been done in pearl millet. Expression studies towards understanding of androgenesis for potential markers have also been carried out in cereals making them model species for DH production. Maize is the third closest relative of pearl millet followed by rice, the first and second being foxtail millet and sorghum (Rajaram et al. 2013). The limited amount of sequence 
information in pearl millet has limited progress in gene discovery and characterization, global transcript profiling, probe design for development of gene arrays, and generation of molecular markers and their application in crop improvement programs. With this rich background in cereals, and the growing interest in pearl millet breeding in the arid and semi-arid regions, it makes a very interesting study to explore technique of anther culture for the induction of androgenesis.

\section{Materials and Methods}

i. Donor plants: Experiments were carried out with seven genotypes 841-P3, 843-22B, ICMB 93333, ICMB 89111, XL-51, 4201 and 86-M34 obtained from Genetic Resources Unit, ICRISAT (International Crops Research Institute for the Semi-Arid Tropics), Patancheru, India. Plants were grown in the green house maintained at $25 / 20{ }^{\circ} \mathrm{C}$ (day/night) under natural light conditions with the intensity varying from $450-600 \mu \mathrm{mol} \mathrm{m} \mathrm{m}^{-2} \mathrm{~s}^{-1}$. A $3: 2: 1$ ratio of red soil, sand and vermin-compost mixture was autoclaved and filled in $30 \mathrm{~cm}$ pots with six plants per pot and a minimum of three pots per variety were maintained. In order to have a continuous supply of florets, fresh batch of sowing was done once the spikes from primary branches have been harvested. All the pots were labeled appropriately. From January to April, the cultivars were grown in the field with temperatures ranging from $22 \pm 2{ }^{\circ} \mathrm{C}(\min )$ to $32 \pm 2{ }^{\circ} \mathrm{C}(\max )$.

ii. Sample, Pre-treatment of buds and sterilization: Spikes/inflorescence of pearl millet still enclosed in the flag leaf, were collected between 8-9 am both from the greenhouse and the field. Whole spikes were cold pre-treated at $4{ }^{\circ} \mathrm{C}$ for either 2 or 7 days. The spikes with and without cold treatment, after removing the flag leaf were surface sterilized using $0.1 \%$ Mercuric chloride with 2-3 drops of Tween 20 for $15 \mathrm{~min}$, washed thrice with sterile distilled water to remove all traces of the surfactant. Care should be taken to dispose of mercuric chloride appropriately as mixing with ground water causes mercury contamination. The microspore developmental stage was confirmed by squashing one anther (out of three present in each spikelet) removed from the spikelet, on a microscopic slide in a drop of $2 \%$ acetocarmine and observed for microspore developmental stage. Only the portion of the spike containing uni-nucleate microspores was used for culture initiation and rest of the spike was discarded.

iii. Culture media, anther culture and observations: Direct culture of anthers and microspores was observed to non-responsive (Mallikarjuna, personal communication) and culture of florets was reported to be most effective (Ha and Pernes, 1982). Hence, sessile florets from sterilized spikes were carefully and aseptically removed with forceps and placed vertically on the solidified agar media. A total of 12 different media were tested with Ch1 media (also used in chickpea anther culture) as the base and varied combination of growth regulators (Table. 1). After the initial induction period, florets with emerged anthers were transferred to growth medium, while some were retained on the original media. Periodic observations were carried by $2 \%$ acetocaramine squashes and observation under light microscope. 
Table 1. Media Used for Anther Culture Experiments in Pearl Millet

\begin{tabular}{|c|c|c|c|c|}
\hline \multicolumn{3}{|c|}{$\begin{array}{c}\text { Components } \\
\text { (mg/lit) }\end{array}$} & \multicolumn{2}{|r|}{$\mathrm{CH} 1$} \\
\hline \multicolumn{3}{|c|}{$\mathrm{NH}_{4} \mathrm{NO}_{3}$} & \multicolumn{2}{|r|}{--} \\
\hline \multicolumn{3}{|c|}{$\mathrm{KNO}_{3}$} & \multicolumn{2}{|r|}{2500.0} \\
\hline \multicolumn{3}{|c|}{$\mathrm{KH}_{2} \mathrm{PO}_{4}$} & \multicolumn{2}{|r|}{170.0} \\
\hline \multicolumn{3}{|c|}{$\mathrm{NaH}_{2} \mathrm{PO}_{4} \cdot \mathrm{H}_{2} \mathrm{O}$} & \multicolumn{2}{|r|}{--} \\
\hline \multicolumn{3}{|c|}{$\mathrm{CaCl}_{2} \cdot 2 \mathrm{H}_{2} \mathrm{O}$} & \multicolumn{2}{|r|}{600.0} \\
\hline \multicolumn{3}{|c|}{$\mathrm{Ca}\left(\mathrm{NO}_{3}\right)_{2} \cdot 4 \mathrm{H}_{2} \mathrm{O}$} & \multicolumn{2}{|r|}{--} \\
\hline \multicolumn{3}{|c|}{$\mathrm{MgSO}_{4} \cdot 7 \mathrm{H}_{2} \mathrm{O}$} & \multicolumn{2}{|r|}{370.0} \\
\hline \multicolumn{3}{|c|}{$\mathrm{FeSO}_{4} \cdot 7 \mathrm{H}_{2} \mathrm{O}$} & \multicolumn{2}{|r|}{27.8} \\
\hline \multicolumn{3}{|c|}{$\mathrm{Na}_{2}$ EDTA } & \multicolumn{2}{|r|}{37.3} \\
\hline \multicolumn{3}{|c|}{$\mathrm{H}_{3} \mathrm{BO}_{3}$} & & 6.2 \\
\hline & & & & 0.83 \\
\hline & $\mathrm{Mn}$ & & & 16.9 \\
\hline & $\mathrm{ZnS}$ & & & 1.4 \\
\hline & $\mathrm{CuS}$ & & & 0.025 \\
\hline & $\mathrm{NaM}$ & & & 0.25 \\
\hline & $\mathrm{CoC}$ & & & 0.025 \\
\hline & Thiar & & & -- \\
\hline & Pyrid & & & -- \\
\hline & Nico & & & -- \\
\hline & Myc & & & -- \\
\hline & L-G & & & -- \\
\hline & & & & 5.0 \\
\hline & Cholecalcif & $\operatorname{tamin}$ D) & & -- \\
\hline & Cynacobalar & $\left.\operatorname{amin} B_{12}\right)$ & & -- \\
\hline & Calcium & nenate & & -- \\
\hline & & & & -- \\
\hline & Glu & & & -- \\
\hline & & & & -- \\
\hline & Casein & sate & & 200.0 \\
\hline & Coconu & $(\mathrm{ml})$ & & -- \\
\hline & & & & 0.265 \\
\hline & & & & -- \\
\hline & & & & -- \\
\hline & & & & -- \\
\hline & & & & 0.530 \\
\hline & & & & 0.09 \\
\hline & & & & 17,000 \\
\hline & & & & -- \\
\hline & & & & 5.8 \\
\hline & & & & -- \\
\hline $\begin{array}{l}\text { Media } \\
(\mathrm{mg} / \mathrm{lt})\end{array}$ & Auxin & $\begin{array}{l}\text { Concentration } \\
(\mathrm{mg} / \mathrm{lt})\end{array}$ & Cytokinin & $\begin{array}{c}\text { Concentration } \\
(\mathrm{mg} / \mathrm{lt})\end{array}$ \\
\hline CHNB & NAA & 2 & BAP & 1 \\
\hline CHNZ & NAA & 2 & Zeatin & 1 \\
\hline CHNT & NAA & 2 & Thidiazuron & 1 \\
\hline CHNK & NAA & 2 & Kinetin & 1 \\
\hline CHN2 & NAA & 2 & 2ip & 1 \\
\hline $\mathrm{CH} 2 \mathrm{~B}$ & $2,4-\mathrm{D}$ & 2 & BAP & 1 \\
\hline $\mathrm{CH} 2 \mathrm{Z}$ & $2,4-\mathrm{D}$ & 2 & Zeatin & 1 \\
\hline $\mathrm{CH} 2 \mathrm{~T}$ & $2,4-\mathrm{D}$ & 2 & Thidiazuron & 1 \\
\hline $\mathrm{CH} 2 \mathrm{~K}$ & $2,4-\mathrm{D}$ & 2 & Kinetin & 1 \\
\hline $\mathrm{CH} 22$ & $2,4-\mathrm{D}$ & 2 & 2ip & 1 \\
\hline
\end{tabular}




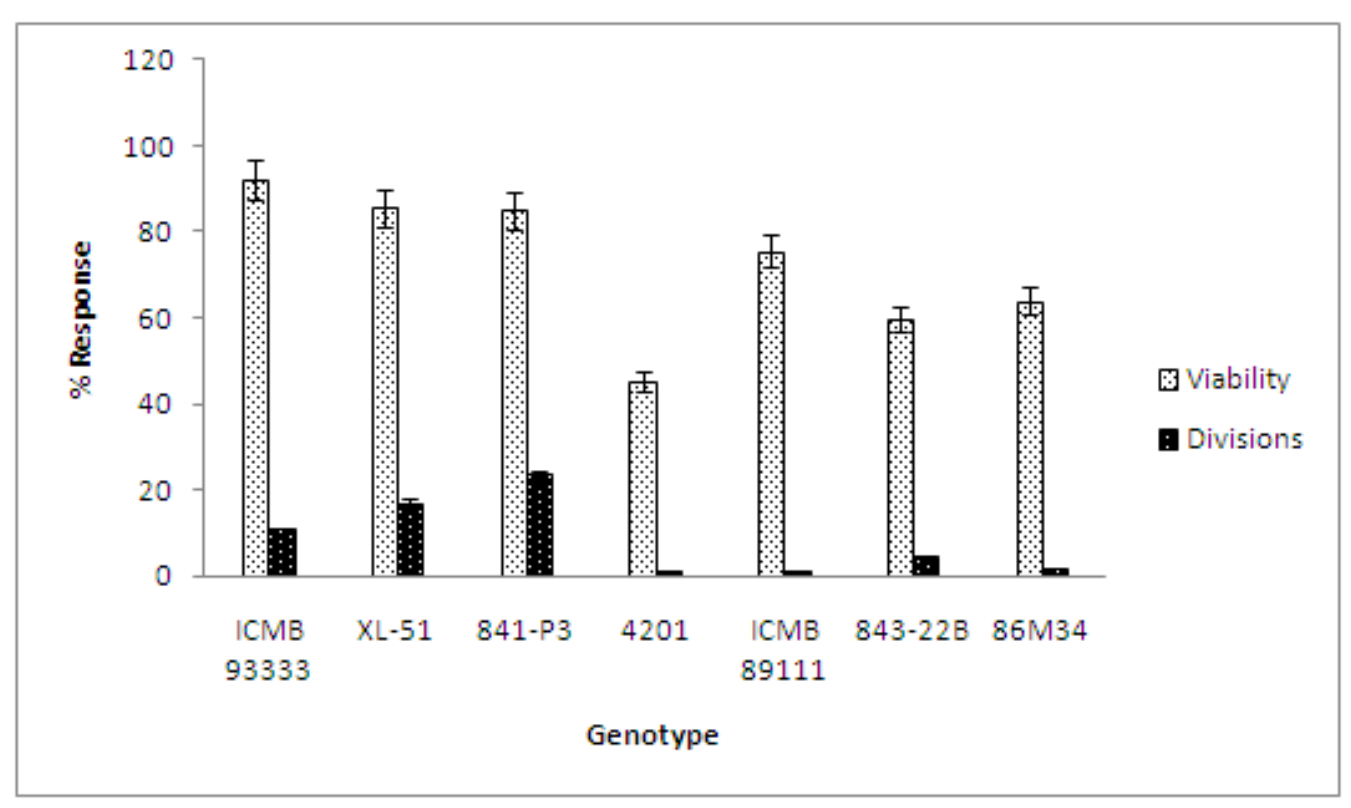

Figure 1. Effect of pearl millet genotypes on microspore viability and androgenesis

\section{Results}

i. Effect of donor plant: Androgenic ability greatly depended on genotype of the explant with varied response among the seven genotypes tested. Maximum average response with respect to anthers with viable microspores after 7 days in culture was observed in ICMB 93333 (92.02\%) followed by XL-51 (85.33 \%) and 841-P3 (84.75\%) and the response was least in the genotype $4201(45.12 \%)$. However, in terms of number of multi-nucleate to multi-cellular microspores per anther, maximum response was observed in 841-P3 (13.7\%) followed by ICMB $93333(9.51 \%)$ and XL-51 (7.8 \%) with the least being $4201(0.21 \%)$ (Fig. 1).

ii. Effect of cold pre-treatment: The panicles of pearl millet that were subjected to cold treatment for 2 and 7 days were non-responsive without any divisions, and turned pale within a week of culture. Anthers emerged out from the florets within 5-8 days in culture when no cold pre-treatment was applied to the i.e. the controls. Also, direct culture of control and pre-treated anthers on semi solid and liquid media with different combinations of plant growth regulators failed to respond. No divisions were observed and anthers turned brown in color after 7 days with pale and empty microspores after 15 days in culture.

iii. Effect of culture media/growth regulators: The culture medium composition varied with respect to growth regulators, $\mathrm{CH}$ medium being the basal medium. Initial experiments were carried out $\mathrm{CH}+$
$1.7 \%$ sucrose, with different combinations of auxins and cytokinins. Each of these media contained one auxin i.e. either 2-4D or NAA in combination with one cytokinin i.e. Zn, Kn, TDZ, 2-ip and BAP. These ten media combinations when used for induction of androgenesis, elicited varied responses under light and dark conditions. Out of these ten combinations, emergence of anthers from florets and higher percentage of viable microspores were observed in $\mathrm{NAA}+\mathrm{Kn}, 2-4 \mathrm{D}+\mathrm{Zn}$ and $2-4 \mathrm{D}+2$-ip under light condition. While six of the ten media i.e. $2-4 \mathrm{D}+\mathrm{Zn}$, 2-4D+Kn, 2-4D+2-ip, NAA+BAP, NAA+TDZ, $\mathrm{NAA}+2-\mathrm{ip}$ and $\mathrm{NAA}+\mathrm{Kn}$ responded in dark condition (Fig. 2). However, after 15 days in culture, multi-nucleated microspores were observed only in 2-4D+2-ip and NAA+2-ip under dark phase. Increase of sucrose concentration to $8 \%$ from earlier $1.7 \%$, enhanced the viability of microspores and also resulted in higher number of dividing microspores under dark incubation conditions in NAA+2-ip and 2-4D+2-ip media. Another medium N6+2-4D+BAP also yielded multi-nucleated and multicellular microspores from three of the most responsive genotypes i.e. 841-P3, ICMB 93333 and XL-51. Continuous cultures on these three media effectively induced multi-cellular microspores by 15 days in culture. Transfer of responsive florets on to a growth medium consisting of $\mathrm{CH}+8 \%$ sucrose $+4 \%$ maltose+2-4D+BAP, (after 15 days in induction media) yielded pro-embryoids and globular embryos after 10 days in culture. 


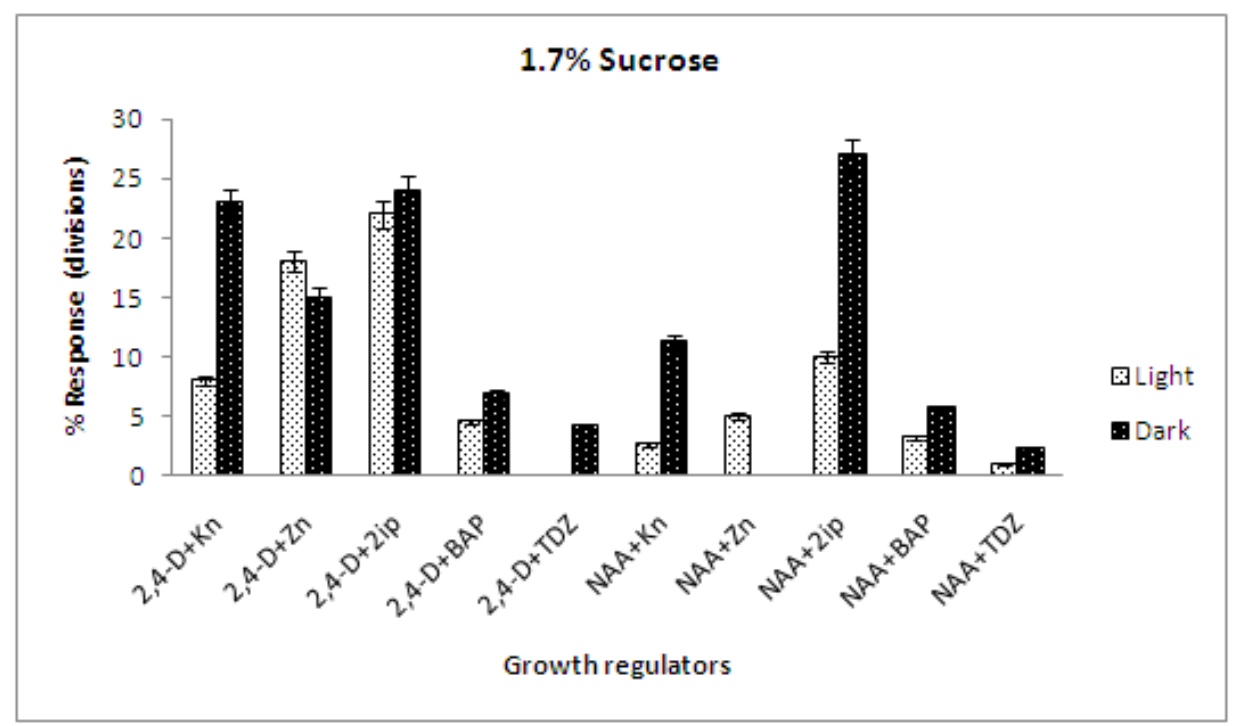

Figure 2a. Effect of light condition and growth regulators on androgenic response in pearl millet

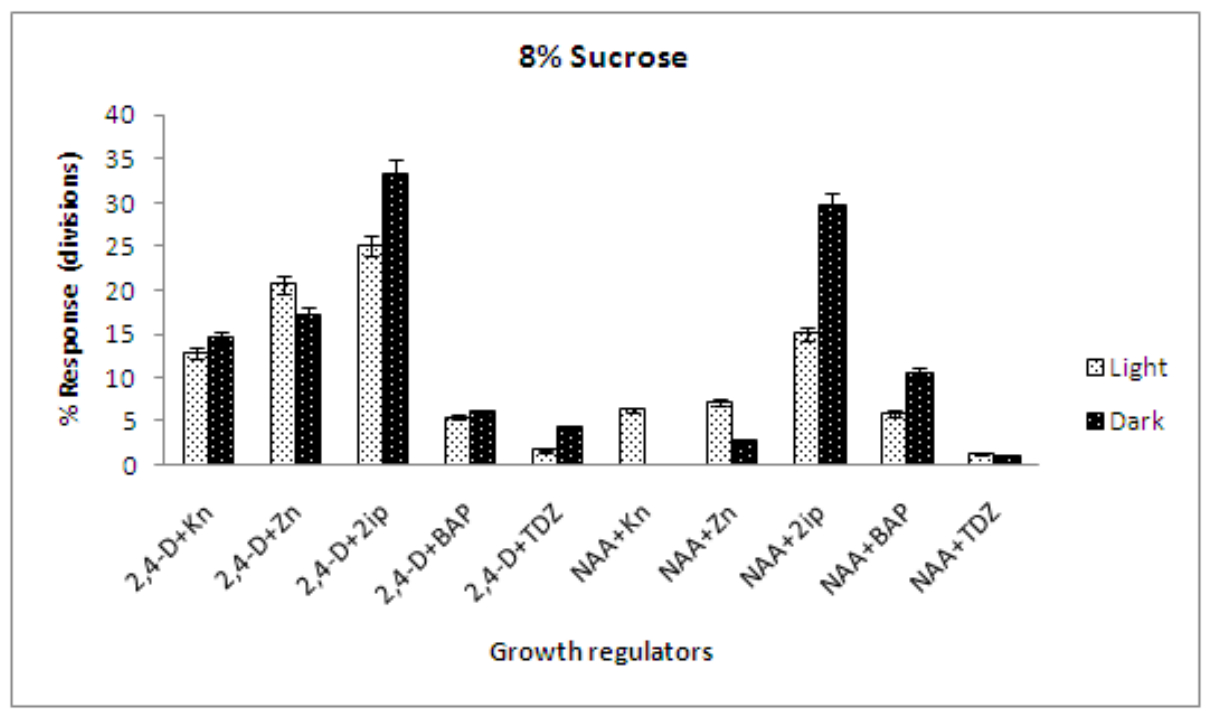

Figure 2b. Effect of light condition and growth regulators on androgenic response in pearl millet

iv. Effect of carbon source and concentration: The availability of carbon at different stages of growth had a significant effect on the rates of induction and production of multi-cellular microspores. The sources of carbon were sucrose and maltose in the experiments conducted. Sucrose was used in two concentrations $1.7 \%$ and $8 \%$ for both induction and further divisions. The anthers from the florets cultured on the $8 \%$ sucrose media emerged out early when compared to $1.7 \%$ sucrose media for all the genotypes tested. Number of viable microspores and induction rates were higher when cultured in media with $8 \%$ sucrose (Fig. 3 ). After 15 days in culture on $1.7 \%$ sucrose medium, most microspores appeared to be pale, light stained and shriveled with very few 4-8 nucleated microspores. In contrast, most microspores were slightly enlarged, round and bright stained with many multi-nucleated microspores with dividing cell walls in high $(8 \%)$ sucrose concentration media. At this stage, transfer of florets to medium containing $8 \%$ sucrose and $4 \%$ maltose resulted in many large multi-cellular microspores containing more than 20 cells per diving microspore. 10 days in this medium post induction in $8 \%$ sucrose media for 15 days, resulted in pro-embryoid like structures in the genotype 841-P3 and many multi-nucleate and multi-cellular microspores in other genotypes ICMB 93333, XL-51 and 843-22B (Fig. 4). However, direct culture of florets on high carbon containing $8 \%$ sucrose $+4 \%$ maltose media did not generate multi-cellular microspores although the viability of microspores was comparable to sucrose (sole source of carbon) containing medium. 


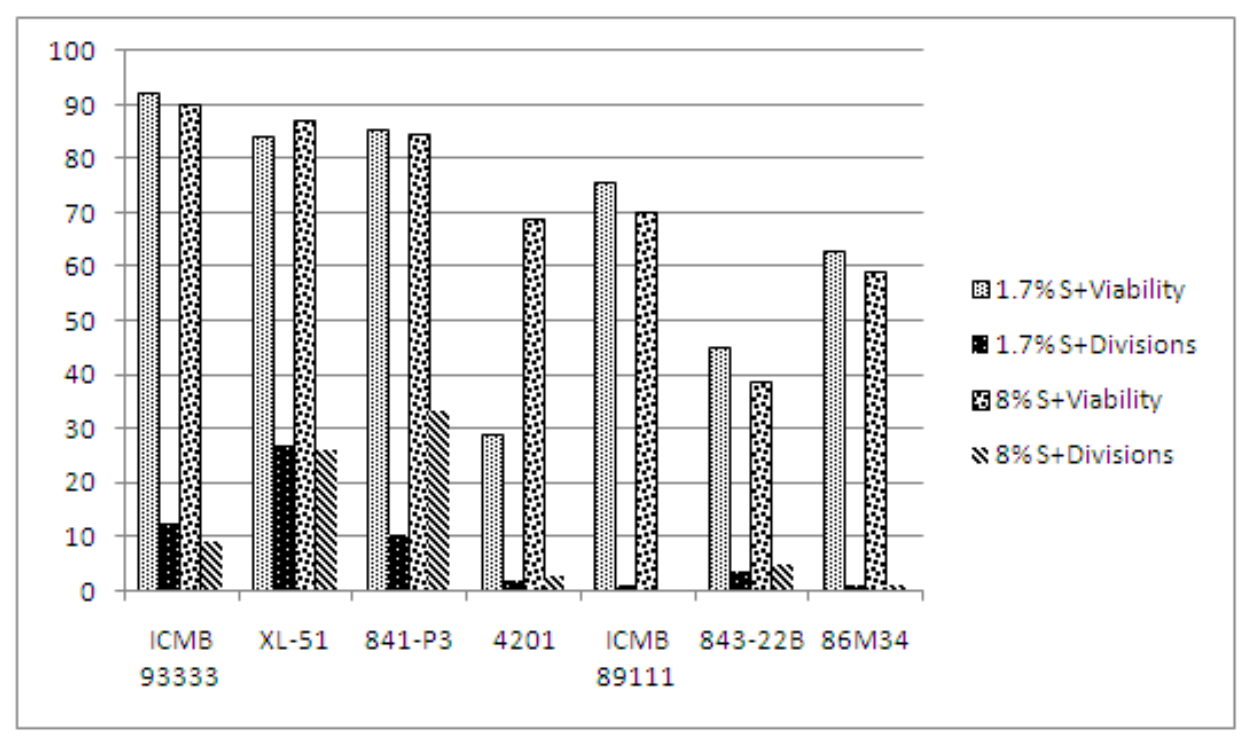

Figure 3. Effect of sucrose concentration on the viability and androgenic response of microspores in pearl millet
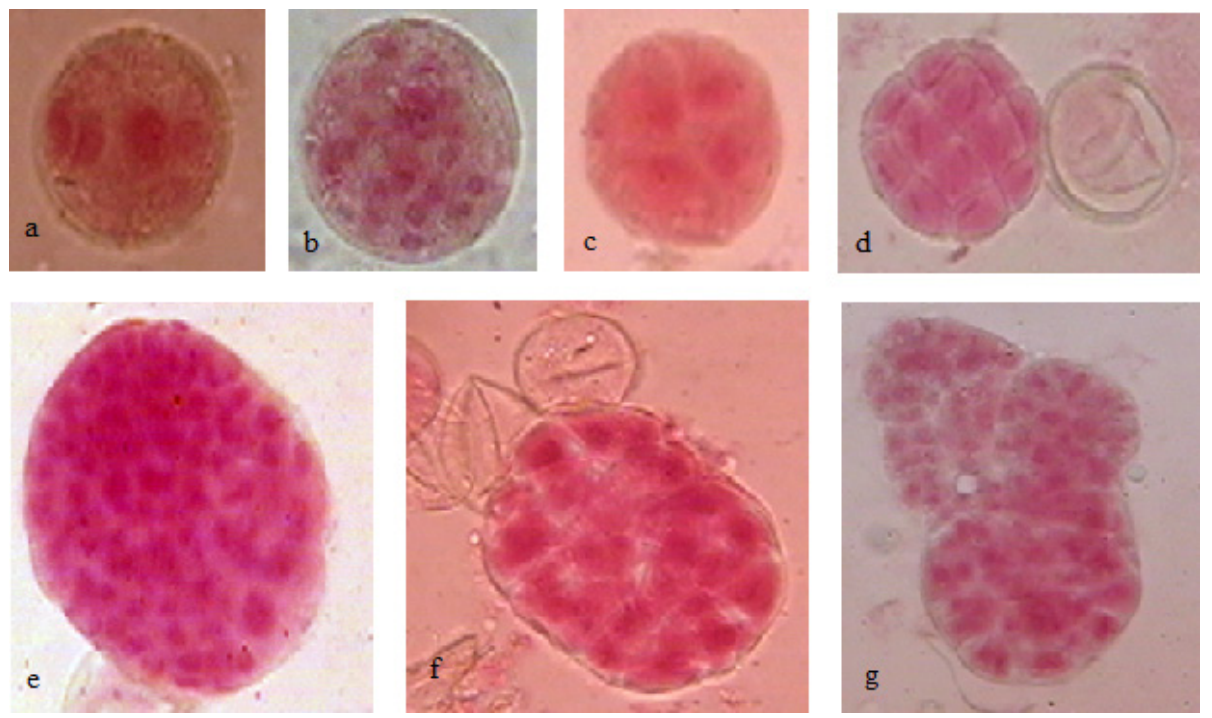

Figure 4. Pro-embryoids of pearl millet, developed after 26 days in culture(a) 4-nucleate, (b) muti-nucleate, (c) 4-celled, (d) multicellular, (e-g) pro-embryoids

\section{Discussion}

Among the seven pearl millet varieties tested, 841-P3 was the best performer resulting in pro-embryoids while 4201 was least responsive. Unlike chickpea, where there is a stark difference between the most and least responsive genotypes, most of the genotypes of pearl millet responded with considerable percentage. Sucrose is the most common source of carbohydrates used in plant tissue culture in a concentration of 2-4\%. Some crops such as Brassica species and cereals prefer higher concentrations of $12-13 \%$ and $6 \%$ respectively. Substitution of sucrose by maltose is known to have genotype-independent plant regeneration and direct embryogenesis in wheat (Bhaojwani and Dantu 2013). In all the genotypes tested in pearl millet experiments, the average response and number of multicellular microspores induced were higher in $8 \%$ sucrose media compared to $1.7 \%$ sucrose. Pro-emryoids were induced when cultured in $\mathrm{CH}$ media with $8 \%$ sucrose and $4 \%$ maltose. Addition of maltose in half the concentration of sucrose significantly enhanced the androgenic response. Addition of brassinosteroids and arabinogalactans to the media which support both induction and growth could potentially reduce the use of multiple media at different developmental stages. These experiments form a promising basis to further develop double haploid protocol in pearl millet breeding which could influence breeding efforts in sorghum, another important cereal of the arid and semi-arid regions.

\section{REFERENCES}


[1] Foster BP, Heberle Bors E, Kasha KJ and Touraev A, "The resurgence of haploids in higher plants", , 2007, Trends in plant science, 12 (8): 368-315.

[2] Jane Murovec and Borut Bohanec, "Haploids and double haploids in plant breeding eds. Plant breeding”, pp. 87-106.

[3] Olmedilla A, "Microspore embryogenesis. E-C. Pua and M.R. Davey (eds.)", 2010, Plant Developmental Biology Biotechnological Perspectives: Volume 2, DOI 10.1007/978-3-642-04670-4_2, Springer-Verlag Berlin Heidelberg.

[4] S. S. Bhojwani and P. K. Dantu, "Androgenesis. Plant Tissue Culture: An Introductory Text, DOI: 10.1007/978-81-322-1026-9_8, 2013, Springer.

[5] Simarro Segui JM and Neuz F, "How microspores transform into haploid embryos: changes associated with embryogenesis induction and microspore derived embryogenesis", 2008, Physiologia plantarum, 134:1.

[6] Germana MA, "Gametic embryogenesis and haploid technology as valuable support to plant breeding", 2011, Plant cell reports, 30 (5): 839.

[7] Maluszynski M, Kasha KJ and Szarejko I, "Published protocols for other crop plant species, In DH production in crop plants: A manual", 2008, Kluwer academic publishers, Dordecht, The Netherlands, pp.309.

[8] Sleper DA and Poehlman JM, "Breeding field crops", 2006, Blackwell Publishing Professional, 5th edition Iowa state press, Ames USA, pp 424.

[9] Brown J and Caligari P, "An introduction to plant breeding", 2008, Blackwell publishing limited, Oxford, UK.

[10] Seymoura Danelle K, Daniele L. Filiault, Isabelle M. Henry, Jennifer Monson-Miller, Maruthachalam Ravi, Andy Pang, Luca Comai, Simon WL Chan and Julian N. Maloof, "Rapid creation of Arabidopsis DH lined for quantitative trait locus mapping", 2012, PNAS, 109 (11): 4227

[11] Chen Z, "Induction of androgenesis in woody plants, In Haploids in higher plants in vitro eds Han $\mathrm{H}$ and Hongyuan", 1986, China Academic Publishers, Springer-Verlag, pp 42-66.

[12] Bhojwani SS, and Razdan MK, "Plant tissue culture: Theory and practice, a revised edition", 1996, Studies in plant science, 5: $167-214$.

[13] Kasha KJ and Maluszynski M, "Production of double haploids in crop plants: An introduction". In Maluszynski M, Kasha KJ, Foster BP and Szaejko I Eds, "Double haploid production in crop plants: A Manual", Kluwer/FAO-IAEA Dordrecht, Vienna, pp 1-4.

[14] Segui- Simmaro JM and Neuz F, "Pathways to doubled haploidy: chromosome doubling during androgenesis", 2008, Cytogenetic and genome research, 120: 358-369.

[15] Wedzony M, Foster BP, Zur I, Golemiec E, Szechynska-Hebda M, Dubas E and Gotebiowska G, "Progress in doubled haploid technology in higher plants, In Advances in haploid production in higher plants. Eds Alisher Touraev, Brian P Foster and S Mohan Jain”, 2009, Springer.

[16] Hesse M, Halbritter H, Zetter R, weber M, Buchnee R, Frosch Radivo A and Ulrich S, "Pollen development, In Pollen terminology.Eds Robert Grant Downton", 2009, Springer, Wein, NY.
[17] Hosp J, Tashpulatov A, Roessnar U, Barsova E, Heberle-Bors $\mathrm{E}$ and Touraev A, "Transcriptional and metabolic profiles of stress induced embryogenic tobacco microspores" , 2007b, Plant molecular biology, 63: 137-149.

[18] Sugui-Simarro JM, "Androgenesis revisited", 2012, the botanical review.

[19] Datta SK,"Androgenic haploids: factors controlling development and its application in crop improvement", 2005, Current science, 89 (11): 1870-1878.

[20] Guha Mukherjee S, "Genotypic differences in the in vitro formation of embryoids from rice pollen", 1973, Journal of experimental botany, 24: 139-144.

[21] Lazar MD, Schaeffer GW and Bacnzinger PS, "Cultivar and cultivar $\times$ environments effect on the development of callus and polyploidy plants from anther culture of wheat", 1984, Theoretical and applied genetics, 67: 273-277.

[22] Datta SK,"Plant regeneration by pollen embryogenesis from cultured whole spikes of barley (vulgare)", 1987, Theoretical and applied genetics, 74: 121-124.

[23] Datta SK and Wenzel G, "Isolated microspore derived plant formation via embryogenesis in Triticum aestivum", 1987, Plant science, 48: 49-54.

[24] Gaillard A, Vergbe P and Beckert M, "Optimization of maize microspore isolation and culture conditions for reliable plant regeneration", 1991, Plant cell reports, 10: 55-58.

[25] Chuong PV and Bevesdorf WD, "High frequency embryogenesis through isolated microspore culture in Brassica napus L. and B. carinata Braun", 1995, Plant science, 39: 219-226.

[26] Chu CC, "The N6 medium and its applications to anther culture of cereal crops. Proceeding symposium plant tissue culture",1978, Science press, Peiking, pp 43-50.

[27] Muraschige T and Skoog F, "A revised medium for rapid growth and bioassays with tobacco tissue cultures", 1962, Phyisiologia plantarum, 15: 473-497.

[28] Data SK, "Androgenesis in cereals, In Current trends in the embryology of angiosperms eds Bhojwani SS and Sih WY. Kluwer", 2001, Academic Publishers, Dordrecht.

[29] Custers JBM, Cordewener JHG, Fiers MA, Massen BTH, Van Lookeren CMM and Liu CM, "Androgenesis in Brassica, In Current trends in the embryology of angiosperms eds Bhojwani SS and Sih WY",2001, Kluwer Academic Publishers, Dordrecht.

[30] Mehran E. Shariatpanahi, Ugur Bal, Erwin Heberle-Bors and Alisher Touraev, "Stresses applied for the reprogramming of plant microspores towards in vitro embryogenesis" , 2006, Physiologia plantarum, 127: 519-534.

[31] Goralski G, Lafitte C. Bouazza L, Matthys Rochon E and Przywara L, "Influence of sugars on isolated microspore development in maize (Zea mays L.)", 2002, Acta boilogica cracoviensia series botanica, 44:203.

[32] Hosp J, Maraschin SF, Toouraev A and Boutilier K, "Functional genomics of microspore embryogenesis", 2007a, Euphytica, 130: 275-285.

[33] Vrinten Pl, Nakamura T and Kasha KJ, "Characterization of cDNAs expressed in the early stages of microspore 
embryogenesis in barley (Hordeum vulgare L.)", 1999, Plant molecular biology, 41: 455-463.

[34] Boutlier K, Offringa R, Sharma VK, Kieft H, Onellet T, Zhang L, Hattori J, Lin CM, Van Lammeren AF, Miki BL, Custers JB and Van Lookeran Campagne MM, "Ectopic expression of BABY BOOM triggers a conversion from vegetative to embryonic growth", 2002, Plant cell, 14: 1737-1749.

[35] Maraschin SF, de Priester W, Spianle HP and Wang M, "Androgenic switch: an example of plant embryogenesis from the male gametophyte perspective", 2005, Journal of experimental botany, 56 (417): 1711-1726.

[36] Peter Pauls K, John Chan, Grant Woronnk, Derek Schulze and Janice Brazolot, "When microspores decide to become embryos-cellular and molecular changes", 2006, Canadian journal of botany, 84: 668-678.

[37] Haldane JBS and Waddington CH, "Doubled haploid versus RILs", 1931, Genetics, 16: 357-374.

[38] Sandra Noir, Anne Brautigam, Thomas Paul B, Jurgen Schmidt and Ralph Panstruga, "A reference map of the Arabidopsis thaliana mature pollen proteome", 2005, Biochemistry and biophysics research communications, 337: 1257-1266.

[39] Vengaldas Rajaram, Thirunavukkarasu Nepolean, Senapathi Senthivel, Rajeev K Varshney, Vincet Vadez, Rakesh K Srivatsava, Trushar M Shah, Ambawat Supriya, Sushil Kumar, Basava Raman Kumari, Bhanuprakash A, Lakshmi Narasu M, Oscar Riera-Lizarazu and Hash CT, "Pearl millet (Pennisetum glaucam L. R. Br.) consensus linkage map constructed using four RIL mapping populations and newly developed EST-SSRs", 2013, BMC Genomics, 14: 159.

[40] Kris Hirst K, Pearl millet (Pennisetum glaucam L.) Domestication and history. Archaelogy.about.com

[41] Martel E, De Nay D, Siljak- Yakovlev S, Brown S and Sarr A, "Genome size variation and basic chromosome number in pearl millet and fourteen related Pennisetum species", 1997, Journal of heredity, 88: 139-143.

[42] George Acquaah, "Principles of plant genetics and breeding" 2007, Blackwell publishing limited, UK.

[43] Bidinger and Hash, "Physiology and biotechnology integration for plant breeding. Eds Henry $\mathrm{T}$ Nguyen, Abraham Blum", 2004, CRC press.
[44] Rai KN, Yadav OP, Suresh K Gupta, Mahela RS and Gupta SK, "Emerging research priorities in pearl millet", 2012, Journal of SAT agricultural research, 10.

[45] Rai KN, Murthy DS, Andrews DJ and PJ Bramel Cox, "Genetic enhancement of pearl millet and sorghum for the semi-arid tropics of Asia and Africa", 1999, Genome, 42: 617-628.

[46] Ramana Kumari Basava, "Development and exploitation of a set of contiguous segmental substitution lines in pearl millet (Pennisetum glaucam (L.) R. Br.)" PhD thesis, Department of genetics, Osmania University, Hyderabad, 2013.

[47] Abs \# 646: "Double Haploid Technology to Develop Near-Isogenic Lines of Wild Mustard (Sinapis arvensis L.) with Auxinic Herbicide Resistance and Susceptibility", Plant Biology 2003: Friday, July 25 - Wednesday July 30, 2003 Honolulu, Hawaii USA.

[48] Datta SK, “Androgenic haploids: Factors controlling development and its application in crop improvement", 2005, Current Science, 89: 11: 1870-1878.

[49] Omilola, B.; Lambert, M, "Weathering the Storm: Agricultural Development, Investment, and Poverty in Africa Following the Recent Food Price Crisis", ReSAKSS Annual Trends and Outlook Report 2009. International Food Policy Research Institute (IFPRI).

[50] Dong-Sheng Han, Yoshiji Niimi, Masalu Nakano, "Regeneration of haploid plants from anther cultures of the Asiatic hybrid lily 'Connecticut King”, 1996/1997, Plant Cell, Tissue and Organ Culture, 47: 2: 153-158.

[51] I. Zur, E. Dubas, A. M. Castillo, M. Krzewska, R. A. Sanchez-Diaz, M. P. Valles, Changes in gene expression patterns associated with microspore embryogenesis in hexaploid triticale (Triticosecale Wittm.)", 2014, Plant Cell Tissue and Organ Culture, 116:261-267.

[52] Sabina Yasmin, Anna Mensuali-Sodi, Pierdomenico Perata, Chiara Pucciariello, "Ethylene influences in vitro regeneration frequency in the FR13A rice harbouring the SUB1A gene", 2014, Plant Growth Regulation, 72: 1:97-103.

[53] H. D. Dharshani Bandupriya, J. George Gibbings, Jim M. Dunwel, "Overexpression of coconut AINTEGUMENTA-like gene, CnANT, promotes in vitro regeneration in transgenic Arabidopsis", 2014, Plant Cell, Tissue and Organ Culture (PCTOC), 116:1:67-79 